\title{
Laparoscopic Gastrectomy after the Age of Eighty: Still a Good Choice?
}

\author{
José Barbosa $^{1,2 *}$, Silvestre Carneiro ${ }^{1,2}$, John Preto ${ }^{1,2}$, Hugo Sousa ${ }^{1,2}$, André Pinho ${ }^{1,2}$, Costa $_{\text {Maia }}{ }^{1}$ \\ ${ }^{1}$ Centro Hospitalar S. João, Oporto, Portugal; ${ }^{2}$ Oporto Medical School, Oporto, Portugal. \\ Email: *Jalbarbosa@netcabo.pt \\ Received July $16^{\text {th }}, 2013$; revised August $14^{\text {th }}, 2013$; accepted August $22^{\text {nd }}, 2013$ \\ Copyright (C) 2013 José Barbosa et al. This is an open access article distributed under the Creative Commons Attribution License, \\ which permits unrestricted use, distribution, and reproduction in any medium, provided the original work is properly cited.
}

\begin{abstract}
Main Goals: Evaluation and comparison of short-term results of totally laparoscopic gastrectomy performed for gastric carcinoma in two groups of patients: older and younger than eighty years. Material and Methods: From 1st January 2011 to 31st October 2012, we have treated 110 patients for gastric carcinoma. 79 patients were submitted to radical gastric resection (the remainder 31 patients either presented with cardia carcinoma or were submitted to palliative treatment). In 33 cases we performed a laparoscopic gastrectomy while in the remainder 46 cases, the open approach was used. The 33 patients operated by a laparoscopic approach were the subject of this study. They were divided in two groups: Group A-patients eighty years old or older (10 cases) and Group B-patients younger than 80 years (23 cases). We evaluated and compared the short-term outcomes of both groups. Results: In all 33 cases, a gastrectomy was performed using a totally laparoscopic approach. There was no need to convert into open surgery. No patient needed to stay in the Intensive Care Unit. One patient needed a night stay in the Post Anesthetic Care Unit, due to subcutaneous emphysema (which resolved within 24 hours). There was a fatality in Group B, due to hepatic failure. The median of the operating time was 224 minutes in Group B and 199 minutes in Group A. The difference was non-significant (pvalue > 0.05). Group A patients were discharged in 6 to 10 days while those in Group B were discharged in 6 to 9 days. Conclusion: The results in this series suggest that totally laparoscopic gastrectomy is effective and safe in patients eighty years old and older, with low morbidity and mortality and short hospital stay. It compares favourably with the results of the same technique applied to younger patients. We suggest that laparoscopic approach to gastrectomy can be used in older patients, allowing them to benefit from the advantages of minimally invasive surgery.
\end{abstract}

Keywords: Gastrectomy; Elderly; Laparoscopic; Minimally; Cancer

\section{Introduction}

The steady increase in life expectancy and better healthcare brought about an increase in surgical patients of advanced age. A good example is the current rise of the number of patients eighty years and older presenting with gastric carcinoma with a resectable tumour. Surgeons often operate these patients with a curative intent.

Gastrectomy is a procedure with non-negligible morbidity and mortality in all patients [1], particularly in older patients [2,3].

The widespread use of minimally invasive surgery brought a reduction of morbidity as well as mortality. Its use in oncologic surgery, mainly colorectal, has proved to warrant outcomes at least as good as those of open surgery.

*Corresponding author.
Gastric minimally invasive surgery has been performed mainly in early gastric cancer for some time in far-eastern countries. In the West this approach suffered a delayed and slow start, probably due to a greater incidence of advanced gastric cancer and a population with a bigger body mass index, which render this operation more complex and time-consuming in the West than in the East.

Laparoscopic gastrectomy is gaining momentum in the West. Its advantages may enable surgeons to reduce the rates of morbidity and mortality. If this proves to be true in old patients too, laparoscopic gastrectomy might widen surgical indications for this group of patients.

\section{Material and Methods}

In our Department we have operated 110 patients for gastric carcinoma, from the 1st January 2011 to the 31st 
October 2012.

All surgeons involved in this series had extensive experience in gastroesophageal surgery for cancer as well as experience in all areas of laparoscopic surgery for esophagogastric benign disease (anti-reflux procedures, miotomy, bariatric surgery, perforated peptic ulcer...). Before the start of this series they already had experience in laparoscopic gastrectomy.

In 79 patients we performed agastric resection with curative intent (the remainder 31 patients either presented with cardia carcinoma or were submitted to palliative treatment).

All patients were operated following a standardized technique, particularly the lymphadenectomy (we advocate a D2 lymphadenectomy).

In 46 cases we performed a standard open gastrectomy and the in remainder 33 cases we used a laparoscopic approach to perform the gastrectomy.

The 33 patients subjected to the laparoscopic approach were the object of this study. We recorded and compared patient demographic data, comorbidities, ASA state, pathologic data and perioperative parameters.

Statistical analysis was performed with SPSS v.20. Continuous variables were compared using the Student t-test and for categorical analysis we used the chi-square test. Values of $\mathrm{p}<0.05$ were considered statistically significant.

The 33 patients were divided in two groups: Group A - patients 80 years old and older (10 cases); Group $\mathrm{B}$-patients younger than 80 years (23 cases).

Before the operation all patients were submitted to antibiotic and thromboembolic prophylaxis. The patients were positioned in the operating table in supine position with a slight procubitus. A pneumatic graduated compression device was applied to the lower limbs.

The surgeon placed himself between the lower limbs, facing the head of the patient, with assistants on both sides of the patient.

Five trocars were used: $10 \mathrm{~mm}$ midline $2 \mathrm{~cm}$ above the umbilicus, $10 \mathrm{~mm}$ in the left mammary line, $10 \mathrm{~mm}$ in the right mammary line, $5 \mathrm{~mm}$ just left to the xiphoid process and $10 \mathrm{~mm}$ in the anterior axillary line, at the umbilical level.

We used 12 to $14 \mathrm{mmHg}$ of $\mathrm{CO}_{2}$ pressure to establish and maintain the pneumoperitoneum.

After the access to the peritoneal cavity was granted, the gastrectomy was performed using in the same standardized steps of the open technique.

We performed either subtotal gastrectomy with Billroth II gastrojejunostomy or total gastrectomy with esophagojejunal Roux-en-Y reconstruction.

In all cases a D2 lymphadenectomy was performed with total resection of the greater omentum.

\section{Results}

33 patients were submitted to laparoscopic gastrectomy, with ages ranging from 25 to 90 years. 10 patients were eighty years old or older while 23 patients were younger than eighty years.

Demographic and clinical data are displayed in Table 1. Mean age was 82.30 years in Group A and 64.25 in Group B. Gender distribution was similar in both groups $(p=0.96)$. Body mass index (BMI) was slightly bigger in Group B-26.55 versus 24.05 in Group A ( $p=0.06)$. Comorbitities and ASA physical status were comparable in both groups ( $p>0.05)$.

Operative and perioperative data are displayed in Table 2. Surgical time was greater in Group B, but the difference did not reach statistical significance. This difference can be explained by the bigger BMI of Group B and by the fact that there are more total gastrectomies in this group of patients (two in Group A and three in Group B).

The post operative period was very similar between both groups, with resumption of oral feeding and time to first bowel movement being similar in both groups ( $p$ > 0.05).

Post operative analgesic consumption was analogous in both groups ( $p>0.05)$.

The number of days from operation to discharge was the similar in both groups.

Morbidity was similar in younger and older patients: in Group A there was a case of subcutaneous emphysema occurring during surgery which resolved spontaneously within 24 hours. In Group B there were two cases of morbidity: a case was submitted to total gastrectomy and had to be reoperated before 24 hours due to bleeding in a trocar site; Another patient, who had undergone a distal gastrectomy, suffered splenic artery thrombosis.

The single perioperative fatality case in the whole series occurred in Group B: a patient suffering from hepatic insufficiency and several other comorbidities, developed post operative hepatic failure eventually leading to death.

The data in Table 3 summarizes the pathological findings.

Tumour size and location were not significantly different in both groups $(\mathrm{p}>0.05)$.

All operations were curative (R0). However in each group there was a case of invasion of the resection margin, not in direct continuity with the main lesion but resulting from the identification of a lymphatic vessel containing tumour cells.

Other pathologic parameters were also similar in both groups, namely the number of harvested lymphnodes (median 27 in Group A and 25.5 in Group B, p > 0.05).

All patients but two are alive and disease free: One patient died from stroke 9 months after surgery, a cause of death probably unrelated to his underlying condition. Another one died in the immediate post operative period, 
Table 1. Demographic data and clinical findings.

\begin{tabular}{cccc}
\hline & Group A & Group B & p-value \\
\hline Age—mean (max/min) & $82.30(90 / 80)$ & $64.25(79 / 25)$ & \\
Gender M/F & $6 / 4$ & $14 / 9$ & 0.96 \\
Body mass index—mean & 24.05 & 26.55 & 0.06 \\
ASA: & & & \\
I & 0 & 3 & \\
II & 7 & 18 & 0.13 \\
III & 3 & 1 & \\
IV & 0 & 1 & \\
Comorbidities (Y/N) & $2 / 8$ & $11 / 12$ & 0.13 \\
\hline
\end{tabular}

Table 2. Operative and postoperative findings.

\begin{tabular}{cccc}
\hline & Group A & Group B & p-value \\
\hline $\begin{array}{c}\text { Operative time } \\
\text { (minutes)—mean (max/min) }\end{array}$ & 199 & 224 & \\
Total Gastrectomy/Subtotal & $(235 / 170)$ & $(300 / 100)$ & 0.850 \\
Gastrectomy & $2 / 8$ & $3 / 20$ & 0.856 \\
Blood transfusion Y/N & $0 / 0$ & $0 / 0$ & \\
Reoperation Y/N & $1 / 0$ & $0 / 0$ & \\
$\begin{array}{c}\text { Analgesic need: } \\
\text { One drug }\end{array}$ & 4 & 11 & 0.678 \\
$\begin{array}{c}\text { More than one drug } \\
\text { Days to start oral }\end{array}$ & 6 & 12 & \\
feeding—-median (max/min) & $4.00(6 / 3)$ & $4.50(6 / 3)$ & 0.819 \\
$\quad$ Days to first & $4.00(6 / 3)$ & $5.00(6 / 2)$ & 0.257 \\
flatus—-median (max/min) & $1 / 9$ & $3 / 20$ & 0.806 \\
$\begin{array}{c}\text { Morbidity Y/N } \\
\text { Length of stay—median } \\
\text { (max/min) }\end{array}$ & $7.00(10 / 6)$ & $8.00(9 / 6)$ & 0.221 \\
\hline
\end{tabular}

Table 3. Pathological findings.

\begin{tabular}{cccc}
\hline & Group A & Group B & p-value \\
\hline $\begin{array}{c}\text { Tumour size (cm)—median } \\
\text { (max/min) }\end{array}$ & $4.10(18 / 1.1)$ & $4.00(18 / 1.0)$ & 0.858 \\
\hline $\begin{array}{c}\text { Tumour location: } \\
\text { Body }\end{array}$ & 1 & 3 & 0.247 \\
Body/Antrum & 2 & 11 & \\
Antrum & 7 & 9 & \\
Depth of invasion (T): & & & \\
T1 & 4 & 9 & 0.217 \\
T2 & 0 & 4 & \\
T3 & 3 & 5 & \\
T4 & 3 & 5 & \\
Retrievedlymphnodes-median & $27.00(47 / 12) 25.50(42 / 10)$ & 0.863 \\
(max/min) & & & \\
Positive lymphnodes-mean & $0.00(20 / 0)$ & $2.60(24 / 0)$ & 0.910 \\
(max/min) & & $1 / 22$ & 0.503 \\
\hline Positive resection margins Y/N & $1 / 9$ & &
\end{tabular}

due to hepatic failure as mentioned before. Both patients were younger than 80 years and both had undergone a distal gastrectomy.

\section{Discussion}

The advantages and the good results of laparoscopic surgery in the treatment of several diseases are widely known. Gastric cancer should be no exception.

There are reports of laparoscopic atypical gastric resections [4] and distal gastrectomy with Billroth II reconstruction for benign ulcer disease [5] dating from the early nineties.

The first laparoscopic gastrectomy for carcinoma was performed by Kitano [6] in 1994. The number of reports of such operations for treatment of early gastric cancer has been increasing, mainly in far-eastern countries. In the West there seems to be a delay in the widespread use of this kind of operation. In any case a wide consensus about the role of laparoscopic gastrectomy in the treatment of advanced gastric cancer is still lacking.

Recently a trend to an increase in the number of reports of short-term results of laparoscopic gastrectomy has been observed in the West. A small number of publications address the long-terms results. However the available data on the matter are still largely insufficient [7].

Several studies, both randomized and non-randomized, evidenced better outcomes for laparoscopic gastrectomy than open gastrectomy. However, most of these studies were carried in the Far East and we can not be certain yet that similar outcomes can be obtained in the West [8].

Some studies did compare perioperative results between open access and laparoscopic gastrectomy $[9,10]$ while some authors studied the influence of age on the outcomes [11-13].

The available data show an advantage of laparoscopic gastrectomy over open gastrectomy concerning perioperative results [12,14-16].

In this study we evaluated a group of patients with a definite risk factor-old age-and we compared them to younger patients operated with the same technique by the same group of surgeons, as some authors did previously $[1,17,18]$.

Although the comorbidity rate was slightly higher in the group of younger patients, the observed difference did not reach statistical significance a fact already observed by other authors who compared younger and older patients presenting with gastric cancer $[11,13,17,19,20]$.

The older patients (Group A) fared as well as the younger ones: There was no mortality and morbidity was minor in this group. Also there was no difference between groups in the post operative period. Therefore our series seems to point that laparoscopic gastrectomy can be applied to older patients with the same profile of effectiveness and safety of the general population.

\section{Conclusions}

We have studied the outcomes of two groups of patients 
submitted to laparoscopic gastrectomy—less than 80 and 80 or greater age. They were matched for other demographic, perioperative and pathological parameters.

Although this is a preliminary study, our results show a clear trend for similar results in both groups.

We postulate that laparoscopic gastrectomy can be safely recommended for gastric carcinoma in patients older than 80 years, with all the advantages of the laparoscopic approach.

\section{REFERENCES}

[1] E. M. Grossmann, W. E. Longo, K. S. Virgo, F. E. Johnson, C. A. Oprian, W. Henderson, et al., "Morbidity and Mortality of Gastrectomy for Cancer in Department of Veterans Affairs Medical Centers,” Surgery, Vol. 131, No. 5, 2002, pp. 484-490. http://dx.doi.org/10.1067/msy.2002.123806

[2] R. Persiani, V. Antonacci, A. Biondi, S. Rausei, A. La Greca, M. Zoccali, et al., "Determinants of Surgical Morbidity in Gastric Cancer Treatment," Journal of the American College of Surgeons, Vol. 207, No. 1, 2008, pp. 1319. http://dx.doi.org/10.1016/j.jamcollsurg.2007.12.050

[3] S. H. Seo, H. Hur, C. W. An, X. Yi, J. Y. Kim, S. U. Han and Y. K. Cho, "Operative Risk Factors in Gastric Cancer Surgery for Elderly Patients,” Journal of Gastric Cancer, Vol. 11, No. 2, 2011, pp. 116-121.

[4] D. L. Fowler and S. A. White, "Laparoscopic Resection of a Submucosal Gastric Lipoma: A Case Report,” Journal of Laparoendoscopic Surgery, Vol. 1, No. 5, 1991, pp. 303-306.

[5] P. Goh, Y. Tekant, C. K. Kum, J. Isaac and N. S. Shang, "Totally Intraabdominal Laparoscopic Bilroth-II Gastrectomy," Surgical Endoscopy-Ultrasound and Interventional Techniques, Vol. 6, No. 3, 1992, p. 160. http://dx.doi.org/10.1007/BF02309093

[6] S. Kitano, Y. Iso, M. Moriyama and K. Sugimachi, "Laparoscopy-Assisted Billroth I Gastrectomy,” Surgical Laparoscopy \& Endoscopy, Vol. 4, No. 2, 1994, pp. 146148.

[7] N. Coburn, R. Seevaratnam, L. Paszat, L. Helyer, C. Law, C. Swallow, et al., "Optimal Management of Gastric Cancer: Results From an International RAND/UCLA Expert Panel," Annals of Surgery, Epub Ahead of Print, 2013.

[8] M. S. Lee, J. H. Lee, D. J. Park, H. J. Lee, H. H. Kim and H. K. Yang, "Comparison of Short- and Long-Term Outcomes of Laparoscopic-Assisted Total Gastrectomy and Open Total Gastrectomy in Gastric Cancer Patients,” Surgical Endoscopy, Vol. 27, No. 7, 2013, pp. 2598-2605.

[9] C. G. S. Huscher, A. Mingoli, G. Sgarzini, A. Sansonetti, M. Di Paola, A. Recher, et al., "Laparoscopic versus Open Subtotal Gastrectomy for Distal Gastric CancerFive-Year Results of a Randomized Prospective Trial,” Annals of Surgery, Vol. 241, No. 2, 2005, pp. 232-237. http://dx.doi.org/10.1097/01.sla.0000151892.35922.f2

[10] E. Mochiki, Y. Toyomasu, K. Ogata, H. Andoh, T. Ohno, R. Aihara, et al., "Laparoscopically Assisted Total Gas- trectomy with Lymph Node Dissection for Upper and Middle Gastric Cancer,” Surgical Endoscopy, Vol. 22, No. 9, 2008, pp. 1997-2002.

[11] K. K. Singh, A. Rohatgi, I. Rybinkina, P. McCulloch and S. Mudan, "Laparoscopic Gastrectomy for Gastric Cancer: Early Experience among the Elderly," Surgical Endoscopy, Vol. 22, No. 4, 2008, pp. 1002-1007.

[12] H. Yamada, K. Kojima, M. Inokuchi, T. Kawano and K. Sugihara, "Laparoscopy-Assisted Gastrectomy in Patients Older than 80,” Journal of Surgical Research, Vol. 161, No. 2, 2010, pp. 259-263. http://dx.doi.org/10.1016/j.jss.2009.01.032

[13] G. S. Cho, W. Kim, H. H. Kim, S. W. Ryu, M. C. Kim and S. Y. Ryu, "Multicentre Study of the Safety of Laparoscopic Subtotal Gastrectomy for Gastric Cancer in the Elderly,” The British Journal of Surgery, Vol. 96, No. 12, 2009, pp. 1437-1442.

[14] M. C. Kim, H. J. Choi, G. J. Jung and H. H. Kim, “Techniques and Complications of Laparoscopy-Assisted Distal Gastrectomy (LADG) for Gastric Cancer,” European Journal of Surgical Oncology: The Journal of the European Society of Surgical Oncology and the British Association of Surgical Oncology, Vol. 33, No. 6, 2007, pp. 700-705.

[15] C. H. Yoo, H. O. Kim, S. I. Hwang, B. H. Son, J. H. Shin and H. Kim, "Short-Term Outcomes of LaparoscopicAssisted Distal Gastrectomy for Gastric Cancer During a Surgeon's Learning Curve Period,” Surgical Endoscopy, Vol. 23, No. 10, 2009, pp. 2250-2257.

[16] H.-H. Kim, W. J. Hyung, G. S. Cho, M. C. Kim, S.-U. Han, W. Kim, et al., "Morbidity and Mortality of Laparoscopic Gastrectomy versus Open Gastrectomy for Gastric Cancer an Interim Report-A Phase III Multicenter, Prospective, Randomized Trial (KLASS Trial)," Annals of Surgery, Vol. 251, No. 3, 2010, pp. 417-420. http://dx.doi.org/10.1097/SLA.0b013e3181cc8f6b

[17] M. R. Brown, N. Bhattacharyya, G. O. McPheeters, J. J. McNamara, "Surgical Resection of Gastric Cancer in the Octogenarian Population,” Journal of Gastrointestinal Surgery, Vol. 3, No. 5, 1999, pp. 561-564. http://dx.doi.org/10.1016/S1091-255X(99)80113-9

[18] K. Yasuda, K. Sonoda, H. Shiroshita, M. Inomata, N. Shiraishi and S. Kitano, "Laparoscopically Assisted Distal Gastrectomy for Early Gastric Cancer in the Elderly,” The British Journal of Surgery, Vol. 91, No. 8, 2004, pp. 1061-1065.

[19] I. B. Shchepotin, S. R. T. Evans, V. A. Chorny, M. Shabahang, R. R. Buras and R. J. Nauta, "Postoperative Complications Requiring Relaparotomies after 700 Gastrectomies Performed for Gastric Cancer,” The American Journal of Surgery, Vol. 171, No. 2, 1996, pp. 270-273. http://dx.doi.org/10.1016/S0002-9610(97)89567-0

[20] H. Yamada, T. Shinohara, M. Takeshita, T. Umesaki, Y. Fujimori and K. Yamagishi, "Postoperative Complications in the Oldest Old Gastric Cancer Patients," International Journal of Surgery, Vol. 11, No. 6, 2013, pp. 467471. 